\title{
Optimal Configuration for Distributed Generations in Micro-grid System Considering Diesel as the Main Control Source
}

\author{
Xiang Chen, Yanbin Li, Junming Xiao and Xuehui Wei \\ Department of Electric Engineering, Zhongyuan University of Technology, Zhengzhou 450007, China
}

Received: February 13, 2015 / Accepted: March 11, 2015 / Published: May 31, 2015.

\begin{abstract}
This paper proposes an optimal configuration of the distributed hybrid renewable generations based on the stand-alone micro-grid system, considering the diesel as the main control source. Due to the natural sources and load of user changes randomly and the non-linearity of the power output by renewable generations, an intelligent optimization method based on the improvement of the genetic algorithm and the control strategy are discussed. The instance analysis is compared with the optimization result of the hybrid system based on HOMER (hybrid optimization of multiple energy resources) and GA (genetic algorithm) method on Matlab software. The simulation result of the optimal configuration showed the new hybrid renewable system and would improve the power supply situation which decreased the cost of energy greatly compared with the conventional form of power supply system which was operated only by diesel. The conclusion of the comparing result between HOMER and GA method shows the advantages of the strategy for the diesel as main control sources.
\end{abstract}

Key words: Distributed generations, renewable generations, micro grid, HOMER, genetic algorithm.

\section{Introduction}

Recently, the application of renewable energy has become one of the solutions to the problems of energy crisis and carbon emission pollution. Besides, it is hoped to improve the people's livelihood who are living in the remote areas or islands, which have difficulty in power supply. So, clean and renewable sources of energy as well as related technologies are being researched extensively. The previous research can lead to a conclusion that, the hybrid distributed power systems exhibit the higher reliability and lower cost compared with the conventional power supply system which was supplied by only one source, such as the island stand-alone power supply system only used the diesel generators.

For the different objects of study, considering the

\footnotetext{
Corresponding author: Xiang Chen, master, research fields: micro grid and new energies. E-mail: cx604190860@hotmail.com.
}

different requirements for the project, the algorithm research turned up multifariously. The stand-alone hybrid power systems were always researched and applied by some models, such as wind-diesel, PV-diesel, wind-PV-diesel and wind-PV-diesel-battery. Some researchers discussed an optimal design model that used the form of PV/wind/battery. Then, they used genetic algorithm to solve the problem of configuration with the power sources [1-4].

Considering controllable load, the study provided an optimization method of genetic algorithm and tabu search in an isolated island in Japan [5]. Considering real-time digital simulator environment, a fast intelligent reconfiguration algorithm based on particle swarm optimization was presented in Ref. [6] for an electric ship's power system.

Many hybrid power system projects were applied worldwide purpose for meeting the demand of power supply in island or other remote areas. Such as, a 
wind-PV-diesel hybrid system was fund for a village in Saudi Arabia. The study of this project provided detailed data and sensitivity analysis for this hybrid power system [7]. The result shows the benefit and advantage in solving the difficulty of power supplying for the remote village and reducing the carbon emission pollution. In another project in Malaysia, the study of optimal sizing and strategy was discussed for PV and micro-hydro hybrid system [8]. It aimed at the best combination of hybrid renewable energy system which had the lowest total net present cost. For the country has the most islands in the world, especially small islands, to increase the electrification ratio, they focus the applications of the renewable energies which can be operated stand-alone and better economy than diesel which was used conventionally.

Many studies were carried out using the HOMER (hybrid optimization of multiple energy resources) software for achieving the performance analysis the diesel-renewable mixed micro-grid system in Refs. [9, 10]. The configuration of the hybrid renewable power supply system is closely linked to the control strategy. In Ref. [11], Sajjad, et al. proposed six mode control strategy for a stand-alone hybrid power system. The strategy was used to control the power flow to meet the demand of users' load based on the measurable system variables.

This paper proposes an optimal algorithm in configuration of the hybrid renewable power system, considering the diesel generators as the main control energy source. For the demonstration project in the island, the model of wind-PV-diesel-battery was used as the form of stand-alone power supply system. Then the economic indicators would be evaluated by TPNC (total net present cost). Referenced the simulation result operated by the soft of HOMER which was used in research for micro-grid and distributed generation power system. The distributed generators combination depends on the value of TPNC.

\section{Research Methodology}

Genetic algorithm is a conventional methodology to solve the problems of the optimal configuration with the distributed power systems. In this study, the diesel generators were considered as the main control source. Therefore, the conventional genetic algorithm was used to improve the new system, and the new control strategies were formulated to improve the economy of the system. This paper mainly considered the output power of wind, PV, diesel and the capacity of battery as the mainly influence factors for the economy research of the system.

\subsection{Wind Turbine Model}

For the wind turbine, the factors of the output power are related to wind speed and tower height. According to the formula of the wind turbine output power by piece wise function as Eq. (1):

$$
P_{w t}(t)=\left\{\begin{array}{cc}
0, & v(t)<v_{c i} \\
a v(t)^{3}-b P_{r}, & v_{c i}<v(t)<v_{r} \\
P_{r}, & v_{r}<v(t)<v_{c o} \\
0, & v(t)>v_{c o}
\end{array}\right.
$$

where, $P_{r}, v_{c i}, v_{c o}, v_{r}$, mean rated power, cut-in wind speed, cut-out wind speed, rated wind speed, respectively. Besides, we ignore the influence caused by tower height in this paper.

\subsection{PV Model}

Considering the solar energy, the electrical power supply is affected by the solar radiation, the panel size and PV cell temperature. Then, the power of the photo-voltaic output hourly is given by Eq. (2):

$$
P_{P V}=P_{S T C} \frac{G_{A C}}{G_{S T C}}\left(1+k\left(T_{c}-T_{r}\right)\right)
$$

where, $P_{P V}$ means the output power of the photo-voltaic; $P_{S T C}$ stands for the max output power in text method under the standard test condition. Always it equals $1 \mathrm{~kW} / \mathrm{m}^{2}$ when the environment temperature is $25{ }^{\circ} \mathrm{C}, \quad G_{A C}$ means illumination intensity; $k$ is the temperature coefficient of output power; $T_{c}$ is the $\mathrm{PV}$ temperature; $T_{r}$ is the $\mathrm{PV}$ 
temperature under standard test conditions.

\subsection{Diesel Generator Model}

The economy of the diesel generator is determined by the oil consumption of unit power. The fuel cost can be calculated as Eq. (3):

$$
C F\left(P_{t}\right)=a_{i} P_{t}^{2}+b_{i} P_{t}+c_{i}
$$

where, $C F\left(P_{t}\right)$ is hourly consumption; $P_{t}$ means the rated power of the diesel; $a_{i}, b_{i}$ and $c_{i}$ are the fuel curve coefficient.

\subsection{Battery Bank Model}

Considering the configuration of the size of the battery bank, the battery's charge and discharge are the main factors. The SOC (state of charge) of the battery bank can be calculated as Eq. (4):

$$
\operatorname{SOC}(t)=(1-Q) \operatorname{SOC}(t-1)+P_{c d} \Delta(t) e_{c d} / E
$$

where, $\operatorname{SOC}(t)$ and $\operatorname{SOC}(t-1)$ are the battery bank state of charge at time $t$ and $t-1 ; Q$ is hourly discharging rate; $E$ is the total energy; $e_{c d}$ is efficiency of charge and discharge.

\subsection{Constraints Model and Control Strategy}

For the complexity of the distributed generations in the hybrid renewable system, the dispatch strategies are curious. In this study, to ensure the reliability and electric power quality of power supply, the diesel was operated as the main control source. So the control and dispatch strategies were discussed as a main point.

In the economic model, the object is to obtain the lowest cost for the stand-alone micro-grid system, and the influencing factors of the cost contain not only the

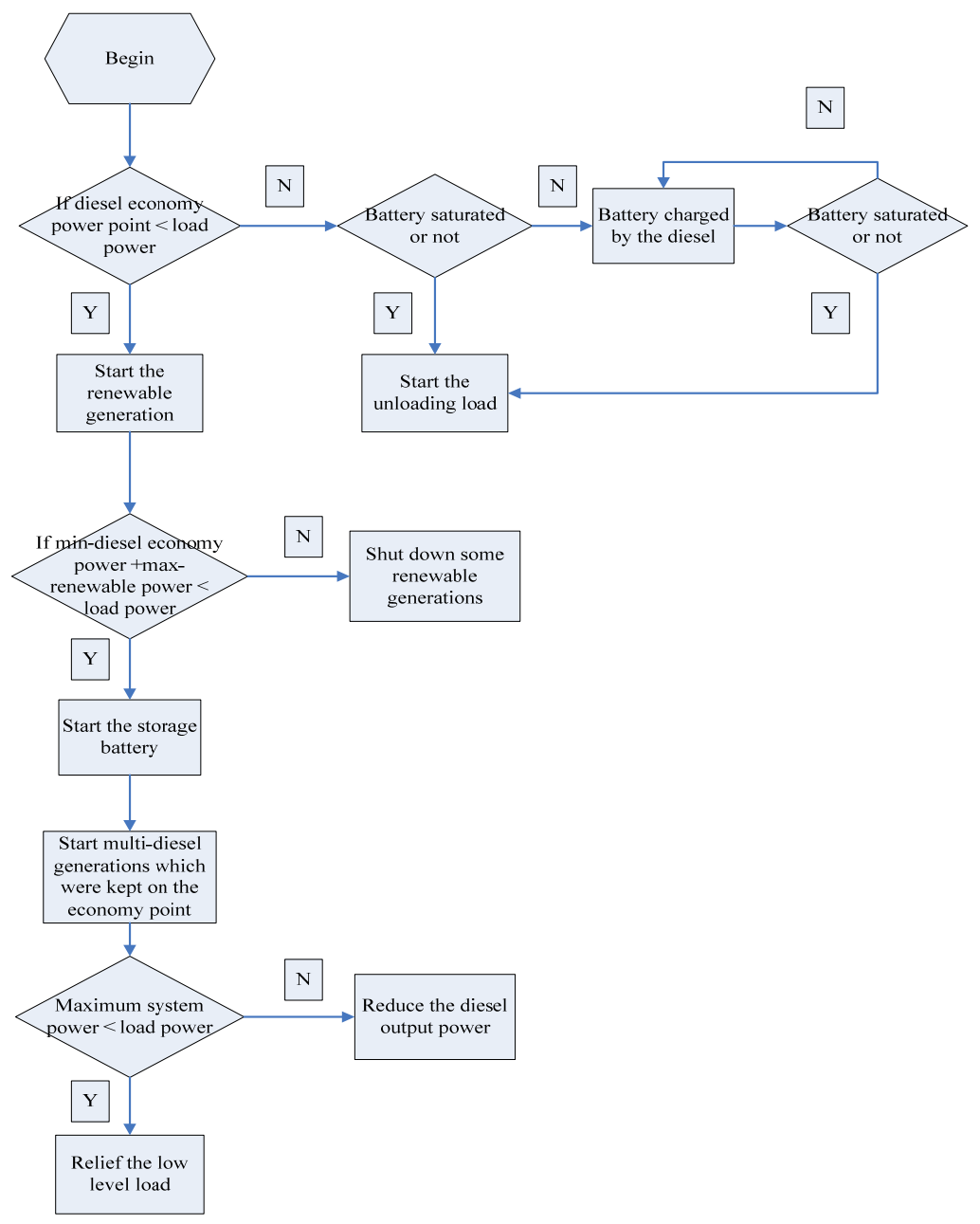

Fig. 1 Control strategy of the hybrid renewable power system. 
cost of the generation devices, but also that of operations and the power output for the each generations. Though we use the same wind turbines, many factors like the locations and wind energy always influence the objective function. The objective function for the total cost of the system was made as Eq. (5), and each model was used for calculating the power output for each generation with the resources data input.

$$
\min \left(T_{c}\right)=\min \sum_{i=1}^{m} a_{i} P_{w i}+\sum_{j=1}^{n} b_{j} P_{s j}+\sum_{k=1}^{h} c_{k} P_{d k}+u V_{s t}
$$

where, $T_{c}$ is total cost of the distributed generations of micro grid system; $P_{w i}$ is the power out of the wind turbine in number $I ; P_{s j}$ is the power out of the $\mathrm{PV}$ in number $j ; P_{d k}$ is the power out of the diesel in number $k ; V_{s t}$ is the capacity of the battery; $a_{i}$ is the coefficient of the cost for the wind turbine in number $i$; $b_{j}$ is the coefficient of the cost for the wind in number $j ; c_{k}$ is the coefficient of the cost for the diesel in number $k ; u$ is the coefficient of the cost for unit capacity of battery.

According to the dispatch strategy, the cost of power generation in hybrid renewable system which consists of distributed generations cost, transmission devices cost, operation and management cost, respectively.

In Fig. 1, with the strategy of the diesel generation as the main control source, the code of the search algorithm which the GA (genetic algorithm) was considered at present aimed to obtain the optimization results, and another new search algorithm would be studied for the better results in the future.

\section{Research Methodology}

Since the natural sources such as the wind and solar energy are in a good condition in this place, the renewable energies have a good prospect. Besides, electric vehicle and electric buses will be supported by government and the public charging stations were to be under construction. The flexibility of micro-grid system control would be increased greatly. The study of the configuration of the hybrid power system is necessary. In this study, we referenced the optimization operated by the software of HOMER.

\subsection{Simulation with HOMER}

HOMER is designed for the hybrid renewable and distributed generation system, and developed by the national renewable energy lab in USA. In this study, HOMER works off grid, and shows how to cost-effectively combine renewable systems with grid power for maximum reliability. The purpose is to meet the electrical load while saving fuel maximally. The information required for the analysis was provided by the local meteorological department and electric power bureau. The final optimal configuration depends on the value of COE (cost of energy).

The model based of HOMER software which is showed in next figure. In Fig. 2, the main components considered in this hybrid system were wind turbine, PV, diesel generator, battery, converter, respectively.

In this study, we referenced the brand of wind turbine manufacturers called Xinsai, the model is XFHJ-100k, the wind turbine's rated power is $100 \mathrm{~kW}$, and unit price is RM700,000 calculated in this study. The price of the PV is RM27,460/kW. Other information required is showed in Table 1.

In Fig. 3, it shows the diagrammatic of the annual solar radiation in the island. The best radiation month is July, and the worst is February. Fig. 4 shows the diagrammatic of the wind speed in the wind farm of

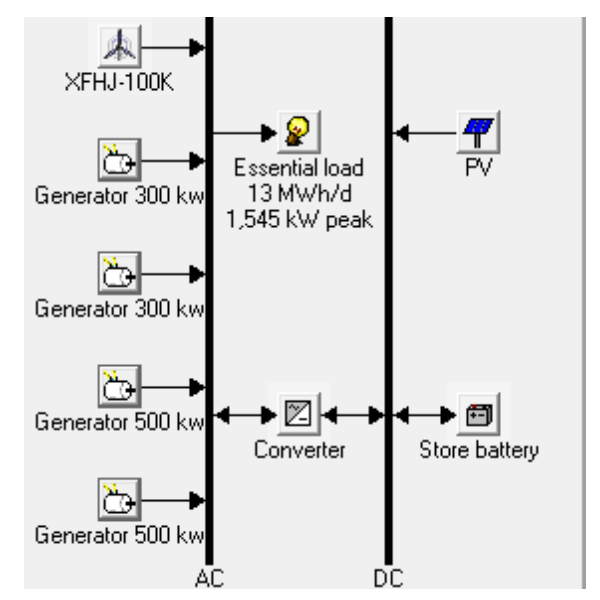

Fig. 2 The model of hybrid renewable system setup. 
Table 1 The input information for the hybrid system.

\begin{tabular}{lllll}
\hline Component & $\begin{array}{l}\text { Size } \\
(\mathrm{kW})\end{array}$ & $\begin{array}{l}\text { Capital Cost } \\
(\mathrm{RMB} / \mathrm{k})\end{array}$ & Replacement $\begin{array}{l}\text { Life-time } \\
\text { (years) }\end{array}$ \\
\hline $\begin{array}{l}\text { Wind } \\
\text { turbine }\end{array}$ & 100 & 700 & 560 & 20 \\
PV & 50 & 1,400 & 1,120 & 20 \\
Diesel & 500 & 500 & 400 & 10 \\
Battery & $3 \mathrm{k} . \mathrm{Ah}, 6 \mathrm{k} 65$ & 65 & 4 \\
Converter & 1 & 100 & 80 & 20 \\
\hline
\end{tabular}

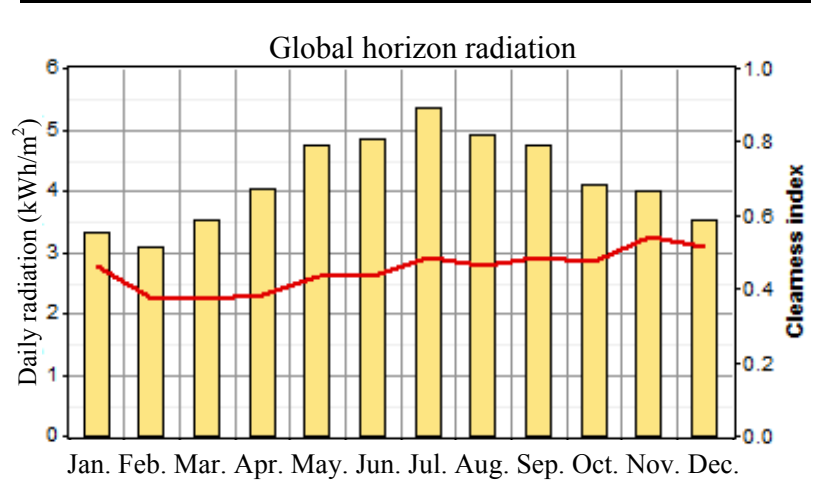

Fig. 3 The annual solar radiation.

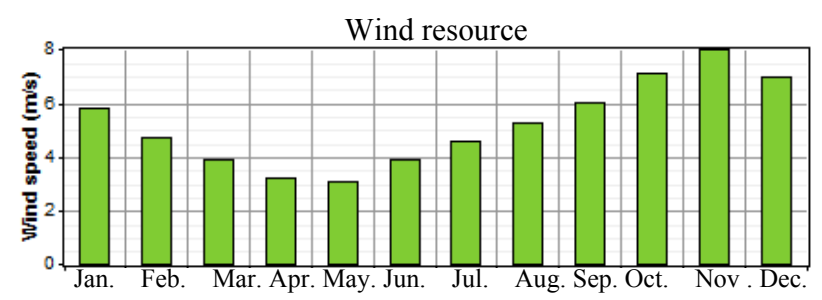

Fig. 4 The annual wind speed. the island. The best month is November and the worst month is April or May. This two kind of natural source has some complementary to each other in the overall trend. Then, the user load in island is showed by Fig. 5. The weather changes randomly, but the statistic data of the natural sources reflect the characteristics regionally and seasonally. So, the hybrid renewable system can use the natural sources complementarily.

With the simulation operated by the soft of HOMER, thousands of simulation configurations were showed by COE (cost of energy) in Fig. 6. It shows the hybrid system consisting of wind turbine, PV, diesel generator, and battery. Make sure every component of the hybrid RE system, the ideal optimization results were showed in Fig. 6.

The model of wind-PV-diesel-battery has the lowest TNPC (total net present cost), the same to the COE of the system approximately RMB2.426/kWh. Meanwhile, the minimum COE, whose model only has the diesel and battery, is higher than the model of wind-PV-diesel-battery system. From the information collected by the local electric power bureau, the COE of the conventional power supply generated by diesel

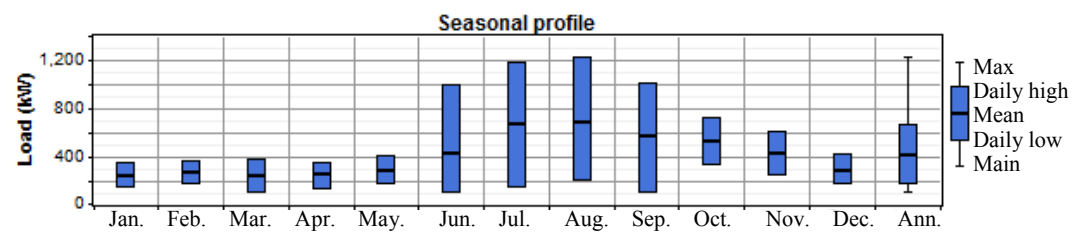

Fig. 5 The annual load.

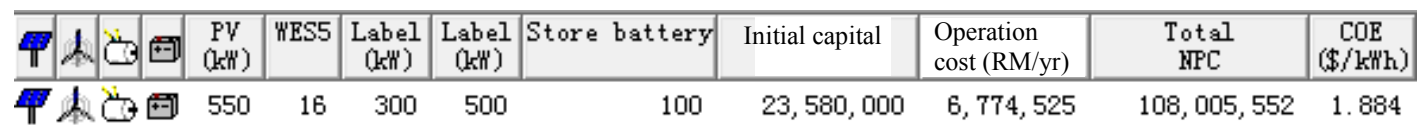

Fig. 6 Optimization results for the RE system with HOMER.

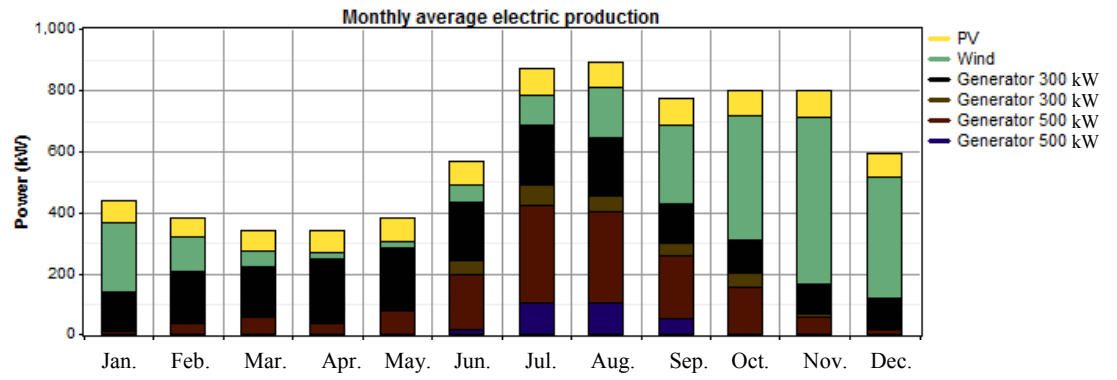

Fig. 7 Monthly electric production of the hybrid RE system. 
Table 2 Optimization results for the RE system based GA.

\begin{tabular}{|c|c|c|c|c|}
\hline Component & WT $(100 \mathrm{~kW})$ & PV $(50 \mathrm{~kW})$ & Diesel (50 kW) & Bat $(6 \mathrm{~kW} \mathrm{3,000} \mathrm{Ah)}$ \\
\hline Quantity & 13 & 3 & 27 & 50 \\
\hline $\mathrm{COE}$ & $1.8825(\mathrm{RM} / \mathrm{kWh})$ & & & \\
\hline
\end{tabular}

is approximately RMB3.03/ $\mathrm{kWh}$. The application of the hybrid renewable system can improve the power supply of the current situation greatly.

In Fig. 7, it shows the monthly average electric production. The composition of the electricity consumption and production can be seen from Fig. 7 . Sum to the information, the highest consumption is in September as it is the tourist rush season. The new coming tourists increase the burden of power supply. On the contrary, the lowest consumption is in April as the tourists rarely come for the bad weather, such as the rainy weather. In another aspect, the wind turbines afford the major power source from October to February as the monsoon climate has brought more wind resources, and it is extremely rich region for the wind resources. For the PV, it provides the power on steady.

\subsection{Simulation with Genetic Algorithm by MATLAB}

In this study, genetic algorithm was discussed to find the optimal configuration of the hybrid system, and the genetic algorithm codes were operated on the MATLAB to gain the optimization result. In the MATLAB simulation, for the diesel generator was considered as the main control source, some new conditions were added into the simulation. Compared with the conventional research on the configuration of distributed generations, the improved genetic algorithms reflect the differences in constraint condition and control strategies. The rated power of the diesel generator is the $50 \mathrm{~kW}$ each, and make sure one of the diesel generators work all the time. The smaller size of diesel generators would increase the flexibility of the strategies diesel generators. The aim of this design is to have more knowledge about the most economic capacity of distributed generations. We ignore the cost of the maintenance caused by increased diesel generators. The detail control strategy is showed in Fig. 1. In these studies, the price of diesel is $7.5 \mathrm{RMB}$ per liter.

In the MATLAB simulation, the original populations have 20 , and the simulation was executed by 200 maximum generations. The crossover value is 0.25 and the mutation value is 0.1 . The fitness value is the reciprocal of the COE and the best value is 0.5312 . The best result is 13 wind generations, $3 \mathrm{PV}$ generation, 27 diesel generations and $50 \times 6 \mathrm{~kW}$ batteries. The result of the optimization shows in Table 2. From Table 2, we can see the optimization result calculated by the improved GA method. The $\mathrm{COE}$ is $1.88 \mathrm{RM} / \mathrm{kWh}$. Compared with the optimization result operated by HOMER, the GA optimization has a great improvement. This method ignores many engineering influences. For example, we consider the limiting case in real engineering so that the diesel can supply the peak load. In this GA method, the insufficient capacity of the diesel generators is made up by batteries when the peak load is coming. And the batteries strategy contributed the great improvement of result. But it is based on the accurate load forecasting techniques. This result is referenced the average load value in recent years. The load forecasting techniques is an important part of these studies of the next stages. Considering the diesel generator as the main control source of the power supply, this strategy has a higher reliability, a higher power quality, as well as much easier control operation and control methods. The optimization result would be put in application. What is more, the simple control strategies avoid the frequent operations of the facilities and equipment, also saving the cost of the operating and management, prolonging the service life of the equipment.

\section{Conclusions}

In this paper, the diesel generator was considered as 
the main control source for the power supply in stand-alone micro-grid system. With the study, the influencing factors can be divided into several aspects, such as the renewable generations of which the output power is nonlinear, the natural sources which changes randomly and irregularly and short-term users' load which also changes randomly and in labile. What is more, the price of the oil is changing all the time but advancing in long term. So the ways of research in optimal configuration were discussed in these aspects, respectively, such as, modeling the distributed generations, making sure the objective functions and constraints, making the control strategy, collecting the weather source data for years, coding the optimization algorithm, and analyzing the optimization result. Besides, the optimal configuration was also studied with HOMER based on the instance of an island demonstration project in China, and the optimization result was compared with that improved by the GA method. Finally, the result would be referenced in the construction of practical engineering.

\section{References}

[1] Ekren, O., and Ekren, B. Y. 2008. "Size Optimization of a PV/Wind Hybrid Energy Conversion System with Battery Storage Using Response Surface Methodology." Applied Energy 85 (11): 1086-101.

[2] Ekren, O., Ekren, B. Y., and Ozerdem, B. 2009. "Break-Even Analysis and Size Optimization of a PV/Wind Hybrid Energy Conversion System with Battery Storage-A Case Study." Applied Energy 86 (7): 1043-54.

[3] Ekren, O., and Ekren, B. Y. 2010. "Size Optimization of a
PV/Wind Hybrid Energy Conversion System with Battery Storage Using Simulated Annealing." Applied Energy 87 (2): 592-8.

[4] Rajkumar, R. K., Ramachandaramurthy, V. K., and Yong, B. L. 2011. "Techno-economical Optimization of Hybrid PV/Wind/Battery System Using Neuro-Fuzzy." Energy 36 (8): 5148-53.

[5] Asato, B., Uchida, K., and Goya, T. 2010. "Optimal Operation for Diesel Generators in Small Isolated Island Power System Cosidering Controllable Load." In Proceedings of the ICEMS (Electrical Machines and Systems), 2010 International Conference on IEEE (Institute of Electrical and Electronics Engineers), 1869-72.

[6] Mitra, P., and Venayagamoorthy, G. K. 2011. "Implementation of an Intelligent Reconfiguration Algorithm for an Electric Ship's Power System." IEEE Transactions on Industry Applications 47 (5): 2292-300.

[7] Rehman, S., Mahbub Alam, M., and Meyer, J. P. 2012. "Feasibility Study of a Wind-PV-Diesel Hybrid Power System for a Village." Renewable Energy 38 (1): 258-68.

[8] Qais, A., Othman, M. M., and Khamis, N. 2013. "Optimal Sizing and Operational Strategy of PV and Micro-hydro." In Proceedings of the 2013 IEEE 7th International PEOCO (Power Engineering and Optimization Conference), 714-7.

[9] Lambert, T., Gilman, P., and Lilienthal, P. 2006. "Micropower System Modeling with HOMER." Integration of Alternative Sources of Energy 1 (15): 379-418.

[10] Razak, N. A., Bin Othman, M. M., and Musirin, I. 2010. "Optimal Sizing and Operational Strategy of Hybrid Renewable Energy System Using Homer." In Proceedings of the 2010 4th International IEEE PEOCO (Power Engineering and Optimization Conference), 495-501.

[11] Sajjad. M., Chowdhury, A. R., and Saha, S. 2012. "Six Mode Control Strategy for a Stand-Alone Hybrid Power System." In 2012 7th International Conference on IEEE ICECE (Electrical Computer Engineering), 611-4. 